\title{
ETHICAL CHALLENGES OF USING BST AND TRANSGENIC ANIMAL
}

\author{
A. S. M. Anwarullah Bhuiyan \\ Associate Professor, Dept. of Philosophy, Jahangirnagar University, Bangladesh \\ E-mail : anwarullah1234@yahoo.com
}

\begin{abstract}
This article examines whether using Bovine Somatotrophin (bST) and Transgenic Animal is compatible with the norms of animal welfare, environment, and public health. We cannot oppose its usefulness all on a sudden. Despite the usefulness of animal biotechnology, we cannot ignore the different adverse effects of this technology. All of these bring forth different ethical challenges. What is the environmental impact of this technology? Another ethical challenge is related to animal's welfare and human's health. In order to assessing the ethical challenges, this article has opted for Mepham's ethical matrix, which is a practical approach for addressing broader policy issues. I have focused on the application of this ethical matrix upon some contexts of animal biotechnology, such as bST and transgenic animal. Through the analysis, this article came to the conclusion that there are no short curt ways to reach an agreement on the application of animal biotechnology.
\end{abstract}

KEY WORDS: ethics, challenges, bovine somatotrophin (bST), transgenic animal

INTRODUCTION: Technological development has brought enormous amount of benefit for the mankind. Apart from this benefit, human beings are also be concerned about the unintended environmental, social, and health-related consequences. Considering this impact, scientists should take into account consequences of any science and accept the greater responsibility for the reasonable application of the scientific result. In doing so, this thesis endeavors to reach the conclusion that biotechnology, specially the field of animal biotechnology, has got a variegated splendor. Different sections of this article give us an understanding of the methodology, key concepts of animal biotechnology, and the implication of ethical matrix upon some contexts of animal biotechnology, such as bST and transgenic animal. Final section of this article is implication of ethical matrix. It is all concerned that animal biotechnology has wonderful contribution, but, we cannot avoid the dangerous potentials of this technology. In this regard, I will devote the ethical controversy of this technology in the final section. Therefore, this article will focus on the application of Mepham's ethical matrix in some contexts of animal biotechnology, such as bST and transgenic animal.

METHODOLOGY: Bovine Somatotrophin (bST), transgenic animal is a development of animal biotechnology. As a technology, it is not a single issue. Rather, it has become a title for a wide range of environmental, public health, and animal welfare-related concerns. Therefore, the solution of the problem is not simple, but complex and multidimensional. To examine the ethical acceptability of animal biotechnology, we need to assess the impact of this technology and its potential effects upon the four interest factors: consumers, farmers and financiers, treated organisms, and environment. In this regard, I have selected Ben Mepham's ${ }^{1}$ ethical matrix, which is a practical approach for addressing broader policy issues in this regard. According to me, ethical matrix is such a theory that it can incorporate the demand of science and its existing multidimensional complexity. In order to evaluate the ethical impact of biotechnology in the fields of agriculture and food, Mepham provides this method of analysis that would help one for facilitate ethical decision making. Mepham's method of ethical matrix is two-dimensional i.e. consequence matrix and evaluative matrix. Consequential matrix, gives a brief description of the assumed or possible consequences of a decision taken upon every affected value, and evaluation matrix, on the other hand, provides an overall picture of the ethical status of the issue at stake. Both the approaches can help us articulate an ethical framework for the technologies applied to the animals. 
Mepham states that it has faced a lot of critiques. He also argues that the approach of four principles is quite applicable only to the realms of biological science, healthcare, and medicine. But, Mepham's ethical matrix is applicable to the fields of agriculture, biotechnology, and food. Not only that "... the framework [four principles] is not an ethical theory and does not aspire to be decision-making procedure" ${ }^{2}$. Therefore, he assumes that Beachump's four principle approaches can hardly satisfy Rawls's non-intuitive means of moral judgment." Due to its limitation, Mepham revises the four-principle approach and offers new ethical tools: "ethical matrix".

In his works, Mepham transforms Beauchamp and Childress's 'four-principles' into three. In the framework of the 'matrix', Mepham combines Beauhamp and Childres's the first two principles (beneficence and non-maleficence) and renames it as the 'respect for well-being'. There are two ingredients in the framework of Mepham's ethical matrix: i. prima facie principles and ii. 'interest groups'. In his framework of ethical matrix, Mepham employs three prima facie principles: well-being, autonomy, and principles of justice. Well-being combines the first two principles of Beachump and Childress: non-maleficeine (avoidance of causation of harm) and beneficence (provision of benefits and balancing them against risks and costs) represent the utilitarian theory. Respect for autonomy represents the freedom of choice and respect for the individual's rights. Theory of justice represents the norms of fair distribution of costs, benefits, and risks. Mepham has shown his ethical matrix through following figure (Figure 1).

Figure 1 : Mepham's Ethical Matrix ${ }^{3}$

\begin{tabular}{|l|l|l|l|}
\hline \multicolumn{1}{|c|}{ Respect for } & \multicolumn{1}{|c|}{ wellbeing } & \multicolumn{1}{c|}{ autonomy } & \multicolumn{1}{c|}{ Justice } \\
\hline $\begin{array}{l}\text { Treated } \\
\text { organism }\end{array}$ & e.g. Animal welfare & e.g. Behavioural freedom & Respect for telos \\
\hline $\begin{array}{l}\text { Producers (e.g. } \\
\text { farmers) }\end{array}$ & $\begin{array}{l}\text { Adequate income and } \\
\text { working conditions }\end{array}$ & $\begin{array}{l}\text { Freedom to adopt or not } \\
\text { adopt }\end{array}$ & $\begin{array}{l}\text { Fair treatment in trade and } \\
\text { law }\end{array}$ \\
\hline $\begin{array}{l}\text { Consumers } \\
\text { (Availability of } \\
\text { safe food) }\end{array}$ & $\begin{array}{l}\text { Availability of safe food, } \\
\text { acceptability }\end{array}$ & $\begin{array}{l}\text { Respect for consumer } \\
\text { choice (labeling) }\end{array}$ & $\begin{array}{l}\text { Universal affordability of } \\
\text { food }\end{array}$ \\
\hline Biota & Protection of the biota & Maintenance of biodiversity & $\begin{array}{l}\text { Sustainability of biotic } \\
\text { Populations }\end{array}$ \\
\hline
\end{tabular}

Mepham states that in the ethical matrix there are twelve individual factors under the following three principles: well being, autonomy, and justice. And there are four stakeholders or interest groups, i.e. treated organisms (animals), producers (farmers), consumers (people), and biota (environment : flora and fauna)) on the vertical axis and three principles on the horizontal axis.

\section{Clarification of the Concepts}

In order to get a clear idea about the problem, it should be explained well what biotechnology means. The term, 'biotechnology', is first used in 1917 by the Hungarian agricultural engineer Karl Ereky who anticipates the term, 'biotechnology', as a "spirit of molecular research" ${ }^{4}$. In his research, he states that every living organism has got 'nucleic acids' which are different from each other in their structure. In 1918, Ereky finds a link between nuclear acids and biotechnology. He takes the term, biotechnology as a "technology based upon biochemistry' ${ }^{5}$. The European Federation of Biotechnology (EFB) accepts the term, 'biotechnology', in the sense of the combination of biology and technology - where the term biology is treated as a branch of knowledge of living organisms and technology as a scientific knowledge. EFB defines the term as an 
"integrated use of biochemistry, microbiology and engineering sciences in order to achieve technological (industrial) application of the capabilities of micro-organisms, cultured tissue cells, and parts thereof" 6 .

In order to develop micro-organisms, improved plants or animals, and to modify food-products, biotechnologies have been used in a wide range of production. This technique is used for transgenic animal's production, commercial products, food production, plant tissue culture, DNA profiling/finger printings, animal tissue culture, pollution control, to safe plants and animal's extinction, prevention-diagnosis, and cure of diseases. According to its use, there are different kinds of biotechnologies can be mentioned as following: a. Industrial biotechnology, b. Environmental Biotechnology, c. Biotechnology as Human Application, d. Health Biotechnology and e. Agricultural Biotechnology. All these types of biotechnology are not my area of focus. Rather, I will focus on bST and transgenic animals as techniques of animal biotechnology.

1. Bovine Somataotrophin (bST): It is one kind of natural occurring growth hormone. At first, bST was commercially produced in the USA as a GM product to be used in animal agriculture. It is produced by biotechnological engineering through recombinant DNA in cultures of the Escherichia coli ${ }^{7}$. It helps stimulate milk productivity efficiency. This hormone is injected to a cow once in every two weeks in order to increase $15-25 \%$ of the milk it produces. ${ }^{8}$

2. Transgenic animals: Transgenic animals are those which have been altered by genetically engineered with an aim to remove genes from them or to insert genes from other species. There are three techniques for producing transgenic animals: (i) recombinant DNA, (ii) retroviruses-mediated gene transfer, and (iii) embryonic stem cellmediated gene transfer. In 1981, biotechnologists produced transgenic mouse by inserting the gene for human growth hormone into a mouse's genome ${ }^{9}$.

IMPLICATION OF ETHICAL MATRIX: This section considers ethical issues raised by the application of animal biotechnology in the field of food production and for medical purpose. In order to assess the ethical impact of this technique, I have selected some of animal biotechnologies, such as Bovine Somatotrophin (bST) and transgenic animal. And, then I have applied ethical matrix in order to ethical evaluation of these technologies.

\section{Case of bST}

Mepham has chosen the case of bST (Bovine Somatorophin) for some particular reasons. In the first case, this technology involves four interest groups: dairy cows, dairy farmers, consumers, and biota. All these stakeholders are accorded ethical standing. Secondly, in the case of bST there are also opposing factors, such as economic efficiency versus animal welfare, and consumer choice versus public health which characterizes bioethical debate. Thirdly, commercial use of bST is also a political issue ${ }^{10}$. Mepham applies his ethical matrix for using bST in dairy farming (Table 2).

Table 2 : The ethical matrix applied to use the bovine somatotrophin (bST) in dairy farming ${ }^{11}$

\begin{tabular}{|l|l|l|l|}
\hline Respect for & Well-Being & Autonomy & Fairness \\
\hline Dairy Farmers & $\begin{array}{l}\text { Satisfactory income and } \\
\text { working conditions }\end{array}$ & $\begin{array}{l}\text { Managerial freedom of } \\
\text { action }\end{array}$ & $\begin{array}{l}\text { Fair trade laws and } \\
\text { practices }\end{array}$ \\
\hline Consumers & $\begin{array}{l}\text { Food Safety and } \\
\text { acceptability } \\
\text { Quality of life }\end{array}$ & $\begin{array}{l}\text { Democratic, informed } \\
\text { choice, e.g. of food }\end{array}$ & $\begin{array}{l}\text { Availability of } \\
\text { affordable food }\end{array}$ \\
\hline Dairy Cows & Animal Welfare & Behavioral freedom & Intrinsic value \\
\hline The Biota & Conservation & Biodiversity & Sustainability \\
\hline
\end{tabular}


Mepham applies three principles in the case of four stakeholders in respect of the use of bST in dairy cows. By analyzing the table, we can present a brief analysis of the ethical matrix in the context of bovine somatotrophin in dairying cows. In the case of bST, there are four stakholder :

a. Dairy Cows. In respect of well-being, organism (here dairy cows) has rights to claim welfare. Now the question is whether the use of bST violates the welfare of dairy cows. Mepham states that different studies have shown that the act of using BST in dairy cows increases the risk of the cow's health. The Monsanto bST production company mentioned in the bST packet label that there are 21 side-effects. Some of these are:

"Increased cystic ovaries and disorders of the uterus; higher incidence of retained placenta; increased risk of clinical and subclinical mastitis; increased digestive disorders such as indigestion, bloat and diarrhea; increased numbers of enlarged hocks and lesions of the knee; disorders of the foot; and injection site lesions which may remain permanent" ${ }^{\prime 2}$.

The European Commission (EC) also shows by referring to different research experiments that the use of bST increases the risk of painful disease which results from the inflammation of the udder, and the risk of clinical mastitis and food and leg disorder, due to long-term administration of bST. The use of bST also reduces the reproductive capability of the cows. A number of other risks are also associated with the use of bST, e.g. increased level of morbidity and mortality. Besides, most of the cows loss their bodily strength at the end of the lactation period. Furthermore, the act of administrating injection to the cow is quite stressful. ${ }^{13}$

There are also adverse side-effects of bST in respect of the principle of autonomy. The act of using bST violates animal behavioral freedom. Cows are then fed a high amount of concentrated food which requires to keep them in indoors. So, there occurs the loss of the opportunity of natural grazing. Different kinds of diseases, such as lameness, clinical mastitis, foot disorder, and other significant risks infringe the behavioral freedom of cows.

Does the use of bST infringe the intrinsic nature of animals? Respect for an animal's intrinsic value does mean that we should not treat them unfairly. This principle claims that a cow as a sentient being should be treated as an intrinsic value. So, we should not merely use it instrumentally. But, "bST use infringes the nature of the animals" ${ }^{14}$.

b. Dairy Farmers. Regarding well-being, it should be mentioned that the farmer' welfare depends on their satisfactory income and working condition. In order to increase economic benefits, dairy farmers use bST for yielding milk of cows. Here economic benefits represent the welfare of dairy farmers. The autonomy of dairy farmers implies that they have got freedom of choosing any farming system. Farmers have got freedom regarding the use of bST. Mepham, in another study of his with Millar et.al, shows that in the United Kingdom $79 \%$ of the dairy farmers do not consider bST use in dairy cows as 'ethically acceptable'. In respect of justice, it can be said that the dairy farmers should be treated fairly by trade laws and practices ${ }^{15}$. It should also be mentioned here that they have got the right to get fair prices for their products.

c. Dairy Consumers. The concept of the consumer's well-being refers to the welfare of the consumer. It refers also to the protection of food from being poisoned or by any other harmful agent. Mepham mentions that in different studies that respect and infringement of the use of bST has been emphasized. FAO and WHO have jointly found out that bST can be used without any applicable health risks to consumers ${ }^{16}$. But, there are also countervailing effects of bST use upon the dairy cows. IGF-1 and related proteins are present in the milk from bST treated cows. IGF-1 is responsible 'to gut pathophysiology, particularly of infants, and to gut associated cancers' and the association between circulating IGF-1 levels and an increased risk of breast and prostate cancer"17. Some other studies have shown that the milk from bST-supplemented cows has got allergic effect upon the human body. In these sense, bSTinserted milk is not safe for the health of the body of human being. 
Regarding consumer's autonomy, it can be said that consumers have got the right to choose whether or not they would consume bST-used dairy products. According to Mepham, consumers' autonomy requires two conditions: firstly, there should be 'voluntariness of consumer'- it means that one has got the freedom to choose to purchase anything, secondly, s/he prefers that the matter of freedom of choice can be ensured by the producer's act of disclosing the information of the products: whether the products are labeled as 'bST-treated cow milk' and 'non-bSTtreated cow milk, ${ }^{18}$ In order to realize the consumer's autonomy, labeling is an important factor while choosing the product. Justice of the consumer in respect of the use bST means that there should be affordability of milk at a reasonable price. Accordingly, if the use of bST can help our power of afford to buy food, then it can be said that consumers are benefitted by this technology.

d. Biota. Using bST in dairy cows has got both positive and negative impact. First of all, its use affects the natural environment. It encourages the intensification of farming, thus resulting in a fewer number of farms. However, these farmers are much larger in size and, consequentially, these appear as the sources of pollution. The silage run-off and excessive fertilizer from the farm jeopardizes biodiversity and sustainability of environment ${ }^{19}$. On the other hand, it has been claimed that the use of bST can help us in an act of curling environmental pollution.

By using ethical matrix, we can reach two diametrically-opposed conclusions: the positive and the negative impact of the use of bST in dairy cattle. A producer can gain more financial benefits by using bST. However, the health risk of the consumers should be taken into account seriously. In the case of dairy cows, the use of bST increases cow's milk productivity, and thus, provides economic benefit to the dairy farmer. In respect of the well-being of the dairy farmers, this is the positive ethical impact of bST. This technology helps us getting more benefits from a less number of cows. However, this will have run-off reduced slur and wastage. Mepham describes this as the 'respect for a principle' ${ }^{20}$. On the other hand, the use of bST has got some negative impact: giving extra metabolic and other load 'infringes' the welfare of the animals. According to Mepham, this is the 'infringement of a principle'. For example, the use of biotechnology (i.e.bST) in animal farming affects environmental sustainability in two different ways. According to Mepham, firstly, bST is profitable in terms of economy to the farmers and therefore, it leads to a concentration of the highly intensive dairy farms. Intensification is also responsible for the existing environmental problem. Secondly, bST has got negative effects upon the environment. It depends on the "fossil fuels, artificial fertilizers, farm and industrial machinery and transportation" ${ }^{21}$.

The process of 'finding the facts' helps the user identify the problems that have arisen from the use of a particular biotechnology. Who will be affected? Which of the effects is best-off? The second step in 'best reasons morality' is 'weighing the facts', which deals with the three ethical principles of matrix: well-being, autonomy, and justice. The use of bST use in the dairy cattle raises some ethical debates. The ethical principles can help the users, producers or even policy makers to weigh the problem. In this regard, we can study the example of Bovine Somatotrophin: 1. Using bST in dairy cattle affects their wellfare, 2. Question of producer's and user's financial benefits due to the use of bST, 3. "Ethically concerned producers are economically harmed." 4. "Ethically concerned producers are potentially coerced", and 5 . Ethical issue is related to biotic conservation ${ }^{22}$.

\section{Case of Transgenic Animals}

The development of animal biotechnology has improved transgenic animal productivity, animal breeding, and the treatment of diseases. Besides, there is also the utility of this technology in healthcare and food production. Transgenic animals, such as cows, pigs, and lambs, have been genetically modified for healthier meat production. It has been claimed that transgenic animals can reduce fat. Xenotranplantation is another important use of transgenic animals. In human transplant surgery, tissues and different organs of transgenic animals are tailored as these are very similar to human cells. However, this act involves ethical concerns in respect of animal welfare particularly the ways we cause their harm and sufferings. The application of this technology has got both long or short term 
environmental and health impact. We can make a clear sense of this problem by applying Mepham ethical matrix in this regard (Table 3$)$.

Table 3 : The ethical matrix applied to transgenic animal

\begin{tabular}{|l|l|l|l|}
\hline Respect for & Well-Being & Autonomy & Justice/Fairness \\
\hline Treated organism & Avoid unnecessary pain & Behavioral freedom & Intrinsic value \\
\hline Producers & Satisfactory profit & $\begin{array}{l}\text { Democratic, } \\
\text { informed choice, } \\
\text { e.g. of food }\end{array}$ & Availability of affordable food \\
\hline Consumers & Improved quality of life & Informed consent & Fair access to genome organs \\
\hline The Biota & Conservation & Biodiversity & Sustainability \\
\hline
\end{tabular}

1. Animal. Is the act of producing transgenic animals compatible with the concept of animal welfare? Through this technology, it is possible to increase animal's well-being, which is affected by deleting the critical diseases of animals which can reduce the high range of animal mortality and also reduce sufferings of animal by the practice of castration and dehorning the agricultural animal ${ }^{23}$. By applying DNA and antibody-based test, it has become possible to diagnose some infectious animal diseases such as, brucellosis, pseadorabis, blue-tongue, foot-and-mouth diseases, avian leucosis, trichinosis, and so on. Farm animal diseases classical swine fever, foot-and-mouth disease, and bovine spongiform can be managed casually through the new improved technology of animal biotechnology. Practicing animal biotechnology in producing transgenic animals for livestock purpose is helpful in improving animal health. This technology is capable of preventing and diagnosing poultry and livestock animal's diseases. And, quick prevention and diagnosis ultimately improve the well-being of animals. Genetic finger-print - a genetic analysis of animal pathogen - is helpful in identifying the sources of the outbreak of diseases, which is quite helpful to monitor the spread of the disease. All these examples show that animal biotechnology offers potential well-being of the animals.

Some other studies ${ }^{24}$ also show that the genetically modified animals are found to be affected by physiological, anatomical, and behavioral abnormalities. Such animals have got poor survival rate of fetuses. They also experience short-life span and critical health risk. For example, the introduction of human $\mathrm{GH}$ to Beltsville pigs results in the high rate of mortality, arthritis, gastric ulcers, infection, degenerative joint disease, and drowsiness ${ }^{25}$.

The genetically modified transgenic animals have also been the target of attention while the purpose of public health is taken into consideration. The ethical controversy of killing animals raises the question about its acceptability. Ethics as an ecocentric sense that raises some questions as to whether we are allowed to modify the components of ecosystem. One most important question is that does the genetic integrity of (transgenic) animals have an intrinsic value that we should not change the form of them? In respect for telos, genetic engineering infringes the nature of animals and its intrinsic value.

Justice in respect of animals indicates the telos of animals. The teleological approach to animals refers to "their design, purpose, or final cause" ${ }^{26}$. Mepham uses the term, 'telos', in the sense of intrinsic value, which refers to the idea of 'integrity'. In different literatures, integrity is used differently. However, the central tenet of this term is "wholeness, fullness, or "unalterdeness" of the animal..." ${ }^{27}$ Telos is also a reflection of the intrinsic characteristics of animals, but genetic tempering affects the design and purpose of animals as well as their intrinsic characteristics. Technological enforcement disrupts the homeostatic processes of animals. In other words, the process infringes the intrinsic nature of the animals by controlling their normal body function. Thus, biotechnology is a potential violation of 'animal integrity' as well as intrinsic characteristics ${ }^{28}$. 
2 Producer. Animal biotechnology can provide great well-being to the producer in terms of economic benefits. The act of biotechnology providing them with less feed (feed is also biotechnologically developed) bought at reasonable prices results in getting more meat, more milk, more eggs, and more wool.

3 Consumer. In everyday life, there are a lot of well-beings that come from the application of animal biotechnology. All these go to the doors of the consumers. Transgenic animals are produced for various purposes. First of all, this technology makes a contribution to the improvement of nutritional value and resistance against critical diseases. For example, pigs, rabbits, and horses are used to produce such products as blood, thinner haparin, anti-venoms, and drug protein. Through this technique, it is possible to produce such therapeutic proteins or antibodies by modifying animals. Transgenic animals are potentially used particularly for curing cancer, hemophilia, rheumatoid arthritis, etc.

Xenotransplantation is another use of transgenic animals. For kidney, heart, and other organs-related diseases, today there is the solution through the replacement by the donors such as pigs and other transgenic animals whose organs and their apeutic cells can be used for the purpose. During the last few decades, pigs's heart valves are successfully used as substitutes for the damaged heart-valves of human beings. However, the risk of Xenotranplantation is another problem of animal biotechnology. There are possibilities of transmitted infectious diseases from one species to another. Some studies show that in the year 1999, 160 peoples received pig cells as part of treatment and they did not show any health hazards ${ }^{29}$. Furthermore, when scientists prepare the organs of animals for Xenotransplantation, they are required to give close attention of the health hazards. In order to avoid health hazards, scientists successfully deleted the gene which is responsible for immune activity from transgenic animals. For this reason, the organs of transgenic animals are not infected by the virus or any lethal micro-organisms. Thus, in this way consumers' well-being can be ensured.

Safety and informed consent would be the possible requirement for consumers in respect of autonomy. Consumer autonomy can be achieved when they get sufficient information about the transgenic animal's products.

Consumer interest can be understood in terms of justice, particularly distributive justice. How are consumers benefited from the application of animal biotechnology in producing transgenic animals? Around the world there is inequality, and most of the people are not capable to afford transgenic organs for their treatment, which are necessary for them. In order to work towards better social equity, it is essential to minimize the impoverished condition. John Rawls argues that no one knows in which economic conditions one will be born. Therefore, every member of the society should wish for equal exposures to risk and that everyone should have the equal opportunity to grow up in an environment that is free from infectious diseases ${ }^{30}$. The theory of justice reveals that every person in the world, irrespective of all conditions, should have the opportunity to use transgenic animals' organs while these become a necessary to them. Sometimes people do not have had the benefits from transgenic animals due to their economic deficiency. In this situation, consumers can be benefited through the reduced prices of the product and the increase of the level of consumer's power to afford such a product.

4 Environment (Biota). Biotechnology in animal sector has brought a dramatic change in the livestock farming in terms of environmental context. The act of improving animal biotechnology offers such developed feed that disposes lower amount of phosphorus and nitrogen in animals' slurry and manure. Some studies show that the normal feeding of dairy cattle disposing 160 million tones of manure annually with high range of phosphorus and nitrogen causes surface and groundwater pollution. But, genetically modified animals can digest feed and dispose less slurry and manure with minimum pollutants. Biotechnologically developed pigs are one such transgenic animals that added gene and enhanced salivary phytose and grown with phosphorus digestibility and retention of phosphorus ${ }^{31}$. In the case of conserving the endangered species, biotechnology shows good results. Transgenic animals are 
environmentally friendly. Recently, genetically modified EnviroPig ${ }^{\mathrm{TM}}$ produce less slur and manures and have lower levels of phosphorus contents which are the causes of environmental pollution.

Reproductive and cloning technology is helpful to conserve the endangered mammals and birds. Omha Zoo veterinarians used this technology (particularly embryo transfer and animal insemination) on three Bengal tigers and Siberian tigers (as a surrogate mother). The endangered species of European mouflon, a smallest wild sheep, has genetically multiplied the number of this species at the University of Teramo, Italy, in 2001. Indian ox-like guar, an endangered species, has been saved by the process of cloning. Recently, the endangered species, Giant Pandas, are being reproduced by using trans-species cloning technology. In 2005, water buffaloes, Arab's champion horses, and Monglian gazelles were cloned to multiply their number.

LIMITATION OF ETHICAL MATRIX: The potential argument comes back to the philosophy of Peter Singer ${ }^{32}$ and Bernard Rolin ${ }^{33}$. Both the philosophers agree that animals should be considered as moral subjects and that any action causing pain is ethically unacceptable. EGE opinion also explicates the sufferings of biotechnologically developed animals which affect animal welfare. Some ecocentric philosophers recommend the extension of moral values to other animal species ${ }^{34}$. All these studies defend the view that animal biotechnology affects animal welfare and, therefore, it should not be acceptable.

The application of ethical matrix in different cells gives different results. In respect of animals, we have got the opportunity to consider the positive and negative consequences of animal biotechnology for their well-being, behavioral freedom, and physical integrity. And, we can assess negative and positive effects of the biotechnologically developed products upon the environment. In respect of the producer, it may be said that ethical matrix provides a judgment of possible economic benefits. Ethical matrix also pays an attention to the consumers' rights. On the one hand, it makes us alert about the hygiene and safety of aspects production, transparent information, and free choice by labeling the product. The principles of justice in the matrix are others important factors of balancing different aspects related to the production of animal biotechnology. For example, the principles of justice indicate what kinds of technology the producers should receive. These also ensure their equal rights of fair access to the free market. At the same time, justice also looks at the animals and environmental integrity in the sense of intrinsic characteristics. Thus, ethical matrix can consistently help us reach a decision by assessing the negative and positive effects of different stakeholders.

However, in most cases ethical matrix discourages to receive any sorts of technology. In this circumstance, where should we stand? Should we ban any kind of practice of bst and transgenic animals? Or, should we encourage this technology? Mepham's ethical matrix provides us with a tool to assess the problem. Mepham himself also states that ethical matrix helps us to facilitate rational decision-making. Different principles of ethical matrix give us different consequences. People can approve the use of bST in cows for yielding milk, producing transgenic for various purposes.

We have also observed that ethical matrix warns us that the use of animal biotechnology has both positive and negative impact. For example, (i) diseases like fibrosis, thallassamia, and muscoviscidosis that we might inherit from our ancestors can be detected by using genetic testing, (ii) vaccines and some other medicines such as insulin meant for curing diabetes are produced by introducing human genes into bacteria, (iii) in order to produce organs for human transplants it is introducing human gene into animals: by using such techniques pigs are used for human heart-valves transplant (iv) large use of animal biotechnology can be recommended in food production. For producing food with high protein, for changing the taste of food, and for producing adequate food by investing lower productive prices are the causes of applying animal biotechnology in our day-to-day world. Ethical matrix, as an ethical tool, shows us the way through which we can detect its adverse effects and enormous benefits. We can also assess which of the animal biotechnology has got longer adverse effects, and which one has got enormous benefits. Ethical matrix provides us 
with an ethical solution to this problem. In the example mentioned above, it is seen that ethical matrix gives us a judgment as to which of the application should be ethically acceptable ${ }^{35}$.

CONCLUDING REMARKS: By observing a number of studies, we can draw the argument that animal biotechnology affects animal welfare, break down the integrity of naturalness and also threat for the public health. On the other hand, animal biotechnology has got various purposes in relation to food and medicine. All of these technologies have given a great opportunity to the human beings. It is also used to experience the use of animal biotechnology for medical purpose. Ethical matrix has shown that the process of using bST, transgenic animals, and other biotechnological products involve a number of ethical concerns that come to play when decisions are to be taken concerning the application of animal biotechnology.

Various problems generated through the application of animal biotechnology can be experienced by ethical matrix. The application of ethical matrix in the case of bST and transgenic animal has shown that there are enormous sideeffects and adverse impact upon the animals and the environment. However, compared to its technological contribution, a transgenic animal has got less effect on different stakeholders. In this regard, we can raise a pertinent question: does ethical matrix provide any concrete ethical decision regarding animal biotechnology? Do we accept it or regret it as unethical means? In any of the products or contribution of animal biotechnology, there is the violation of three cells: animal's well-being, animals' behavioral freedom, and the telos or intrinsic characteristics of animals.

In conclusion, it can be said that ethical matrix is based on the weighing of pros and cons of the fact. It leads us to the conclusion that there are no short curt ways to reach an agreement on the application of animal biotechnology. There are various contexts and controversies including the relationship between technology and societal norms, and the relationship between animal integrity and human beings, and the question of substantial equivalence between technologically-developed products and naturally-developed products.

\section{REFERENCES:}

1 Mepham, T. B., "Ethical Analysis of Food Biotechnologies: an Evaluative Framework," in B. Mepham (ed.), Food Ethics, London and New York: Routledge, 1996, pp. 101-119.

Mepham, T.Ben., "A Frameworks For Ethical Analysis of Novel Foods : the Ethical Matrix" , Journal of Agricultural and Environmental Ethics, 2000a Vol.12, Issue : $2: 165-176$.

Mepham, T.Ben, "The Role of Food Ethics in Food policy", In Proceedings of the Natural Society, 2000b, 59, 609618.

Mepham,B., Kaiser M, Thorstensen E, Tomkins S and Millar K, Ethical Matrix Manual ,LEl, The Hague, 2006.

http://www.ethicaltools.info/content/ET2\%20Manual\%20EM\%20(Binnenwerk\%2045p).pdf (accessed at $10 \mathrm{am}$, 01 April 2010)

2. Mepham, 2000a, p. 167.

3 Mepham, 1996.

4 Fari and Kralovanszky, "The Founding Father of Biotechnology", International Journal of Horticultural Science, 2006, 12 (1): 9-12, p.10.

5 Fari \& Kralovanszky, 2006, p.10.

6 Becker, Gerhold, "Biotechnology-The New Ethical Frontier: An Introduction", Changing Nature's Course :The Ethical Challenge of Biotechnology, eds by Gerhold K. Becker associate with James P. Buchanan, Hong Kong : Hong Kong University Press, 1996, p.1.

7 Mepham, Kaiser et.al., 2006 , p.32.

8 Mepham, 2005, Bioethics: An Introduction for the Biosciences, Oxford University Press, USA, pp.52-53.

9 BIO, Guide to Biotechnology, Biotechnology Industries Organization, New York, 2007, p.71.

10 Mepham, 2005, p.54. 
11 Mepham , $2005: 54$.

12 cf Mepham, 1996, pp. 108-109.

13 cf. Mepham, 2000b, p. 613.

14 Mepham, 1996, p.109.

15 Millar, et.al., 1995, p. 195.

16 Mepham, 2000a, p.96.

17 Mepham, 2000a, p.96.

18 Mepham, 2005, p.59.

19 Mepham, 2000b, p.613.

20 Mepham, 2000b, p. 613.

21 Mepham, 1996, p. 111.

22 Schoreder and Palmer, Schroeder, Doris and Palmer, Clare, 2003. "Technology Assessment and the Ethical Matrix" in Poiesis Praxis, 1.2003, p.300.

$23 \mathrm{BIO}, 2007$, p.71.

24 EGE,. European Commission Group of Advisers on the Ethical Aspects of Biotechnology, 1993. The Ethical Implications of the Use Performance-enhancers in Agriculture and Fisheries,( Rapporteurs M. Warnock and M. Sinisalo), 1993.

25 EGE, 2008, p.12.

26 Munro, L., "The Future Animal: Environmental and Animal Welfare Perspectives on the Genetic Engineering of Animals", Cambridge Quarterly of Health Care Ethics, Vol, 10, 2001, p.315.

27 CeBRA "Ethics and Farm Animal Cloning Risks, Values and Conflicts", from the Report Project of Cloning in Public: A Specific Support Action within the 6th Framework Programme, Priority 5: Food Quality and Safety, Coordinator: Danish Centre for Bioethics and Risk Assessment (CeBRA), (2005). Source: http:// www.bioethics.kvl.dk accessed on 30 May, 2010, p.16.

28 Bruce, D. Should We Clone Animals ? 1998. http://www.srtp.org.uk/clonan3.htm, accessed on 05 June, 2010.

Gjerris, M. "Ethical Aspects of Animal Cloning", Proceedings from the 21st Scientific meeting of the European Embryo Transfer Association, 2005, pp.79-93.

29 BIO,. Guide to Biotechnology, Biotehnology Industries Organization, New York, 2007, p.37.

30 Rawls, John, A Theory of Justice, Oxford: Oxford University Press, 1971, p.448.

$31 \mathrm{BIO}, 2007$, pp.74-75.

32 Singer P., 1990. Animal Liberation N.Y.: Avon Books.

33 Rollin B., 1998. The Unheeded Cry: Animal Consciousness Animal Pain and Science, Oxford : Oxford University Press.

34 Naess A., "In Defence of Deep Ecology", Environmental Ethics, 1984, 6(3):265-270.

35 See for details :

Bhuiyan, A. S. M.A, 2010. "Ethical Challenges of Animal Biotechnology", MAE thesis, published in :

URL : http://liu.diva-portal.org/smash/record.jsf?pid=diva2:359860, Linkoping University, Sweden.

Acknowledgement: I am grateful to Professor Dr. Anders Nordgren, Prof of Bioethics, Linköping University, Sweden, for comments on my earlier draft of this paper. The paper is the part of my Master Thesis, submitted (2010) to the center for Applied Ethics, Linkoping University, Sweden. 